\title{
OPEN Comparison of plant growth and remediation potential of pyrochar and thermal desorption for crude oil-contaminated soils
}

\author{
Noshin llyas ${ }^{1 凶}$, Uzma Shoukat ${ }^{1}$, Maimona Saeed ${ }^{1}$, Nosheen Akhtar ${ }^{1}$, Humaira Yasmin ${ }^{2}$, \\ Wajiha Khan ${ }^{3}$ \& Sumera Iqbal ${ }^{4}$
}

Crude oil contamination is a serious environmental threat for soil and plants growing in it. This study provides the first experimental evidence for comparison of the efficacy of pyrochar (slow pyrolysis biochar), thermal desorption and their combined application for degradation of crude oil contaminated soil $(0 \%, 10 \%$, and $20 \%)$, and growth of lettuce under glasshouse conditions. Pyrochar was produced by pyrolysis of sawdust at $350^{\circ} \mathrm{C}$, whereas thermal desorption was done by soil pyrolysis at $500^{\circ} \mathrm{C}$. Soil incubations were done for 120 days. The results of soil analysis showed that the crude oil degradation efficiency for the combined application was highest (40\%), whereas pyrochar and thermal desorption was $25 \%$ and $19.6 \%$, respectively. The maximum degradation products of crude oil were manifested by the detection of low molecular weight hydrocarbons (ranged between 173 and 422) in the soil with combined application treatment using Gas Chromatography-Mass Spectrometry (GC-MS) analysis. Crude oil contamination significantly reduced the germination and growth of the lettuce plants. Similarly, the combined application also improved plant growth by an increase of $24 \%$ in germination percentage, $35.5 \%$ in seedling vigor index, and $27 \%$ in promptness index under $20 \%$ crude oil contamination. Remediation caused a significant increase in fresh and dry biomass ( $40 \%)$, leaf area (30\%), total chlorophyll (21\%), water potential (23.6\%), osmotic potential (27\%), and membrane stability index (40\%). Moreover, there was an increase in the contents of proline (32\%), total amino acids (29\%), soluble sugars (37\%), proteins (27\%), and antioxidant enzymes such as superoxide dismutase (19\%), catalase (33\%) and peroxidase (38\%). This study confirmed the efficacy of pyrochar (slow pyrolysis biochar), thermal desorption, and their combined application for crude oil decontamination of soil at laboratory scale and also in improving soil usability by improved germination and growth of lettuce.

The release of petroleum oil in soil and water, due to various human activities, is posing severe threats to our environment. Petroleum hydrocarbons are considered very hazardous to living organisms due to their toxicity, mutagenicity, and carcinogenicity ${ }^{1}$. Contamination of soil with oil results in serious depression of growth of most plants, primarily due to its effects on the physical and chemical properties of soil and soil water relations ${ }^{2}$.

Crude oil affects the environment by changing the essential elements of habitat. To overcome this problem, different soil remediation technologies have been developed such as soil washing with surfactants, biological treatment, thermal treatment, air stripping etc. ${ }^{3}$. Thermal desorption treatment has been considered one of the very promising technique due to its possible applications to a wide range of organic contaminants and some heavy metals (Hg), converting them to volatile forms. Nowadays, pyrolysis is being done during which the contaminated soil is heated between 350 and $500{ }^{\circ} \mathrm{C}$, which also reduces heat requirement from 40 to $60 \%$ as compared to other conventional heating methods ${ }^{4}$. According to Ren et al. ${ }^{5}, 10 \mathrm{~min}$ of pyrolysis at $250{ }^{\circ} \mathrm{C}$ of soil containing diesel reduced total petroleum hydrocarbons from 6272 to $359 \mathrm{mg} / \mathrm{kg}$. However, it affects soil porosity and properties, which are not easy to be recovered ${ }^{6}$.

${ }^{1}$ Department of Botany, PMAS-Arid Agriculture University, Rawalpindi, Pakistan. ${ }^{2}$ Department of Biosciences, COMSATS University Islamabad (CUI), Islamabad, Pakistan. ${ }^{3}$ Department of Biotechnology, COMSATS University Islamabad, Abbottabad Campus, Pakistan. ${ }^{4}$ Department of Botany, Lahore College for Women University, Lahore, Pakistan. ${ }^{\circledR}$ email: noshinilyas@yahoo.com 


\begin{tabular}{|l|l|c|}
\hline \multirow{2}{*}{ Treatments } & Degradation rate (\%) & 20\% oil contamination \\
\cline { 2 - 3 } & $\mathbf{1 0 \%}$ oil contamination & $8.5 \pm 0.01 \mathrm{a}$ \\
\hline Control & $11.25 \pm 0.5 \mathrm{~d}$ & $16.12 \pm 0.1 \mathrm{~b}$ \\
\hline Pyrochar & $25.09 \pm 0.02 \mathrm{~b}$ & $14.75 \pm 0.5 \mathrm{c}$ \\
\hline Thermal desorption & $19.65 \pm 0.05 \mathrm{c}$ & $32.31 \pm 0.02 \mathrm{a}$ \\
\hline Pyrochar + Thermal desorption & $40.15 \pm 0.1 \mathrm{a}$ & \\
\hline
\end{tabular}

Table 1. Degradation rate of hydrocarbons in control, pyrochar, and thermal remediated soil. This data displays the means and standard deviation $(n=3)$. Different letters show significant differences $(\mathrm{p}<0.05)$ following the order $\mathrm{a}>\mathrm{b}>\mathrm{c}>\mathrm{d}$.

Pyrolysis through the carbonization of biomass at processing temperatures of above $300{ }^{\circ} \mathrm{C}$ under oxygen-free conditions, produces pyrochar. Pyrochar is a new and effective soil amendment which can maintain soil nutrient and enhance carbon sequestration. Pyrochar also shows great potential for water conservation and water use efficiency improvement under greenhouse cultivation. Pyrochar has a high potential for carbon sequestration and acts as activated carbon and can be effectively used in soil bioremediation processes ${ }^{7}$. Moreover, pyrochar has improved physical and chemical properties and has the potential for soil amendment, carbon sequestration, pollution remediation, and bioenergy production ${ }^{8}$.

Lettuce (Lactuca sativa L.) plant is very sensitive towards soil hydrocarbons ${ }^{9}$. Lettuce seed and growth bioassays can be effectively used for the evaluation of soil toxicity due to contamination ${ }^{10}$. Seed germination assays, particularly of lettuce, can predict phytotoxicity of contaminated soils $\mathrm{s}^{11}$. Marti et al. ${ }^{12}$ used lettuce growth parameters as an indicator of the toxicity of soil samples.

Thermal desorption is a very effective technique for decontamination of oil-polluted soils but thermal treatments lead to changes in soil fertility and water levels which can limit its use for vegetation ${ }^{4}$. In contrast, biochar has less remediation potential but can change the soil physicochemical properties ${ }^{13}$, improve the water holding capacities of the soil ${ }^{14}$ eventually resulting in increased soil fertility ${ }^{15}$; with potential beneficial effects on crop productivity, plant establishment, and growth ${ }^{13}$. Hence, the integration of thermal desorption with the biochar amendment can not only lead to enhanced remediation of crude oil but can also prove effective for better plant growth. Currently, to the best of our knowledge, there is no published record on the comparison of pyrochar and thermal desorption, alone or in the combined application. In this study, we have investigated the remediation of crude oil contaminated soil through pyrochar addition and thermal desorption of crude oil-contaminated soil. Treated soils were used to study the germination of lettuce and its morphological, physiological, and biochemical responses were used as indicators for soil toxicity.

\section{Results}

The present research was designed to observe the remediation potential of a new combined application technique i.e. pyrochar (slow pyrolysis biochar); thermal desorption alone and their combined application in the crude oil-polluted soil. We found that this new combined application was effective not only in remediating the soil but also neutralized the toxic nature of crude oil.

Soil analysis. Crude oil contamination negatively affected soil properties by causing a decrease in soil $\mathrm{pH}$ ( $3 \%$ and $7 \%$ at $10 \%$ and $20 \%$ contamination), EC ( $10 \%$ and $28 \%$ at $10 \%$ and $20 \%$ contamination), and soil moisture content $(27.6 \%$ and $41.5 \%$ at $10 \%$ and $20 \%$ contamination). Results showed a significant reduction in available nutrients. The nitrogen, phosphorous, and potassium showed a maximum reduction by 29 and $40 \%, 7 \%$, and $15 \%$, and to trace quantities at $10 \%$ and $20 \%$ contamination, respectively as compared to the non-contaminated soil. However, organic carbon improved significantly by two and three times, at $10 \%$ and $20 \%$ contamination. Pyrochar improved soil characteristics not only under control conditions but also under oil contamination. Thermal desorption had little effect on soil properties. Soil amendments with pyrochar and thermal desorption improved the properties of soil.

The most promising results were shown by the combined application resulting in $30 \%$ and $27.3 \%$ increase in soil moisture content at $10 \%$ and $20 \%$ contamination, $40 \%$ and $23 \%$ increase in nitrogen contents at $10 \%$ and $20 \%$ contamination, $10-3 \%$ in phosphorous content and from trace level to detectable amounts in potassium for $10 \%$ and $20 \%$ contaminated soil, respectively (Supplementary Table 1).

Crude oil degradation. The effect of pyrochar and thermal desorption on the degradation of hydrocarbons was significant $(\mathrm{p} \leq 0.5)$. An inverse relationship exists between the rate of hydrocarbon degradation and the level of oil contamination as hydrocarbon degradation decreased with an increase in the oil contamination. Treatment of soil with a combined application of pyrochar and thermal desorption showed more promising results of $40.1 \%$ degradation of hydrocarbons which is 30 folds greater as compared to control one at $20 \%$ level of crude oil. The addition of pyrochar showed 25\% hydrocarbon degradation which is 13.8 times more compared to the control one. While $19.7 \%$ of degradation of hydrocarbons was recorded with thermal desorption as compared to control one. The degradation order of effectiveness is combined application treatment $>$ pyrochar $>$ thermal desorption $>$ control (Table 1). So, a combined application of pyrochar and thermal desorption is more effective and is suggested as possible remediation of hydrocarbon contamination. An inverse relationship 


\begin{tabular}{|c|c|c|c|c|c|}
\hline Treatments & Retention time & Peak area(\%) & Compound & Molecular formula & M.W \\
\hline \multirow{3}{*}{ Control } & 15.3 & $71,785 \times 10^{3}$ & Butyldodecyl ester & $\mathrm{C}_{24} \mathrm{H}_{38} \mathrm{O}_{4}$ & 390.6 \\
\hline & 19.11 & $121,541 \times 10^{3}$ & Butyltetradecyl ester & $\mathrm{C}_{26} \mathrm{H}_{42} \mathrm{O}_{4}$ & 384.59 \\
\hline & 23.18 & $61,452 \times 10^{3}$ & Triacontane & $\mathrm{C}_{30} \mathrm{H}_{62}$ & 422.81 \\
\hline \multirow{5}{*}{ Pyrochar } & 11.13 & $75,694 \times 10^{3}$ & 9H-Flourine, 9-methylene & $\mathrm{C}_{14} \mathrm{H}_{30}$ & 178 \\
\hline & 14.24 & $45,861 \times 10^{3}$ & 2-Bromotetradecane & $\mathrm{C}_{14} \mathrm{H}_{29} \mathrm{Br}$ & 276 \\
\hline & 17.11 & $65,319 \times 10^{3}$ & Hexdecane & $\mathrm{C}_{16} \mathrm{H}_{34}$ & 226 \\
\hline & 22.44 & $51,823 \times 10^{3}$ & Pyrene & $\mathrm{C}_{16} \mathrm{H}_{10}$ & 202 \\
\hline & 26.42 & $35,481 \times 10^{3}$ & Tridecane 1-iodo & $\mathrm{C}_{13} \mathrm{H}_{29} \mathrm{I}$ & 310 \\
\hline \multirow{4}{*}{ Thermal desorption } & 12.15 & $54,291 \times 10^{3}$ & Heptadecane & $\mathrm{C}_{17} \mathrm{H}_{36}$ & 240.48 \\
\hline & 16.32 & $47,523 \times 10^{3}$ & Heptadecane 6,10 tetrmethyl & $\mathrm{C}_{21} \mathrm{H}_{44}$ & 296.16 \\
\hline & 23.45 & $42,156 \times 10^{3}$ & 7,9 Di-tert-butyl-1-oxaspiro(4,5) & $\mathrm{C}_{17} \mathrm{H}_{24} \mathrm{O}_{3}$ & 276 \\
\hline & 26.56 & $34,612 \times 10^{3}$ & Phthalic acid bis(7-methyloctyl) ester & $\mathrm{C}_{26} \mathrm{H}_{42} \mathrm{O}_{4}$ & 418 \\
\hline \multirow{6}{*}{ Combined application } & 10.53 & $58,432 \times 10^{3}$ & Dodecane & $\mathrm{C}_{12} \mathrm{H}_{26}$ & 170.33 \\
\hline & $13.4 ` 2$ & $42,713 \times 10^{3}$ & Undecane 3,8 dimethyl & $\mathrm{C}_{13} \mathrm{H}_{28}$ & 200.36 \\
\hline & 19.11 & $52,341 \times 10^{3}$ & Dodecane 2,6,11, trimethyl & $\mathrm{C}_{15} \mathrm{H}_{32}$ & 212 \\
\hline & 19.45 & $34,267 \times 10^{3}$ & n-Hexadeconic acid & $\mathrm{C}_{16} \mathrm{H}_{32} \mathrm{O}_{2}$ & 256 \\
\hline & 23.16 & $54,243 \times 10^{3}$ & Hexadecane & $\mathrm{C}_{16} \mathrm{H}_{34}$ & 226 \\
\hline & 26.54 & $45,261 \times 10^{3}$ & Flouranthene & $\mathrm{C}_{16} \mathrm{H}_{10}$ & 202 \\
\hline
\end{tabular}

Table 2. The end products and metabolites of crude oil produced by degradation by pyrochar, thermal sorption, their combined application and contaminated soil.

exists between the rate of hydrocarbon degradation and the level of oil contamination as hydrocarbon degradation decreased with an increase in the oil contamination. (Table 1).

GC-MS analysis. GC-MS analysis of soil samples for the identification of compounds being generated after the degradation of crude oil. The results suggested that crude oil was degraded in soil by different treatments after the 120 days' trial. The mass spectrometer identified the hydrocarbon constituents using the NIST Library. We found a range of compounds (aliphatic and aromatic) with different molecular weights (173-422). The data generated the total ion chromatograms, which revealed that the transformations of parent compounds (crude oil) are associated with the production of metabolites. The metabolites generated during the degradation of a quaternary mixture of PAHs provided useful information about the biodegradation process. GC-MS analysis showed that high molecular weight compounds were degraded, and the peak area indicated the presence of hydrocarbons in soil (Table 2). After 120 days' trial, the products of soil treated with combined application treatment were Dodecane, Undecane 3,8 dimethyl, Dodecane 2,6,11, Trimethyl, $n$-Hexadeconic acid, Hexadecane, and Flouranthene. These possibly originated from the synergistic effect of pyrochar and thermal desorption. Whereas, pyrochar and thermal desorption resulted in the production of a lesser number of compounds (9H-Flourine, 9-methylene, 2-Bromotetradecane, Hexdecane, Pyrene were produced by pyrochar whereas thermal desorption produced Heptadecane, Heptadecane 6,10 tetramethyl, 7,9 Di-tert-butyl-1-oxaspiro $(4,5)$, Phthalic acid bis (7-methyl octyl) ester). Overall, the GC-MS analysis showed that combined application treatment degraded PAH into more number of lesser molecular weight compounds and thus more effective in decontamination.

Plant germination. The effect of soil remediation through pyrochar, thermal desorption, and their combined application had shown a significant effect $(p \leq 0.05)$ on the germination of two lettuce varieties. Crude oil stress decreased the germination percentage up to $29.7 \%$ and $39 \%$ in $10 \%$ and $20 \%$ contaminated soil as compared to the control. Application of combined application (pyrochar and thermal desorption) resulted in $28.5 \%$ and $21.8 \%$ increase in germination percentage of both lettuce varieties as compared with respective control stress of $10 \%$ and $20 \%$ contaminated soil. There was a $24 \%$ and $17.5 \%$ increase in germination percentage by pyrochar and $19 \%$ and $12.3 \%$ by thermal desorption $10 \%$ and $20 \%$ contaminated soil. The seedling vigor index also increased by $35.5 \%$ and $28.7 \%$ by pyrochar and thermal desorption remediation in $20 \%$ contaminated soil. Similar trends were observed in the promptness index (Supplementary Fig. 1).

Plant morphology. Plant fresh and dry biomass (Fig. 1) showed a considerable decrease (30\% and $40 \%$ in $10 \%$ and $20 \%$ contaminated soil) and leaf area (25\% and $30 \%$ in $10 \%$ and $20 \%$ contaminated soil). We found that combined application treatment had the most pronounced results by showing a maximum increase of plant biomass up to $40 \%$ ( $10 \%$ contamination) and $22 \%$ (20\% contamination), respectively. Soil amendment with pyrochar helped to mitigate the effect of crude oil and increased by $30 \%$ and $38 \%$ biomass at $10 \%$ and $20 \%$ contaminated soil. Whereas, thermal desorption improved growth by $12 \%$ (10\% contamination) and $10 \%(20 \%$ contamination). Both varieties performed well in response to the degradation potential of pyrochar, thermal desorption, and their combined application (Fig. 1). 


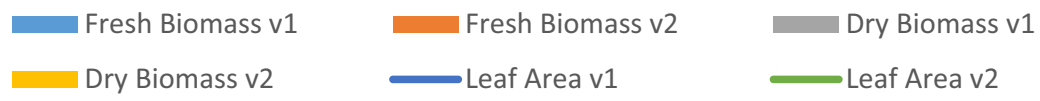

35

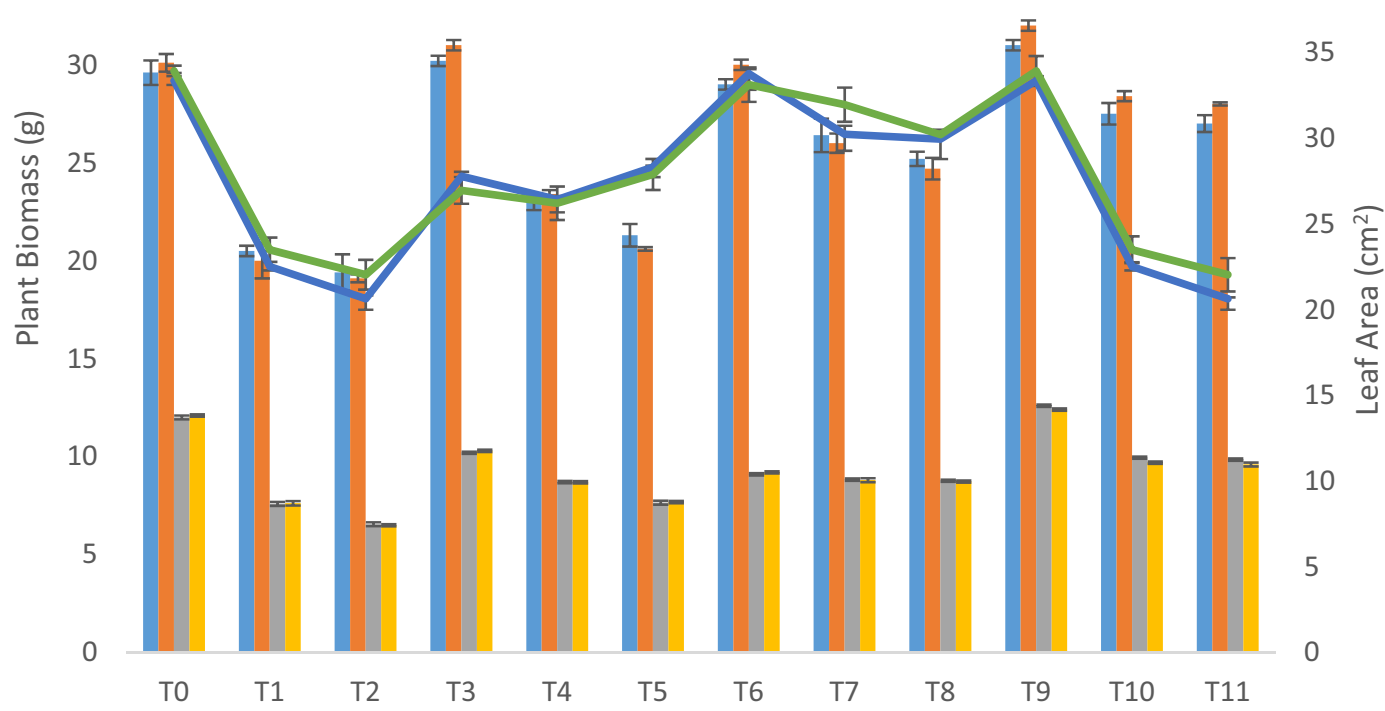

Figure 1. Fresh and dry biomass and leaf area of two lettuce varieties growing in crude oil contaminated, pyrochar, thermal desorption, and their combined application remediated soil. Detail of treatments: Where, T0 $=$ control soil, T1 $=10 \%$ crude oil contaminated soil, T2 =20\% crude oil contaminated soil, T3 = Pyrochar treated control soil, T4 $=$ Pyrochar $+10 \%$ crude oil contaminated soil, T5 $=$ Pyrochar $+20 \%$ crude oil contaminated soil, T6 $=$ Thermal desorption control soil, T7 $=$ Thermal desorption $+10 \%$ crude oil contaminated soil, T8 $=$ Thermal desorption $+20 \%$ crude oil contaminated soil, T9 $=$ Pyrochar + Thermal desorption control soil, T10 $=$ Pyrochar + Thermal desorption $+10 \%$ crude oil contaminated soil, T11 = Pyrochar + Thermal desorption $+20 \%$ crude oil contaminated. soil V1 = Iceberg, V2 = Boston. This data displays the means and standard deviation $(n=3)$. Different letters show significant differences $(\mathrm{p}<0.05)$.

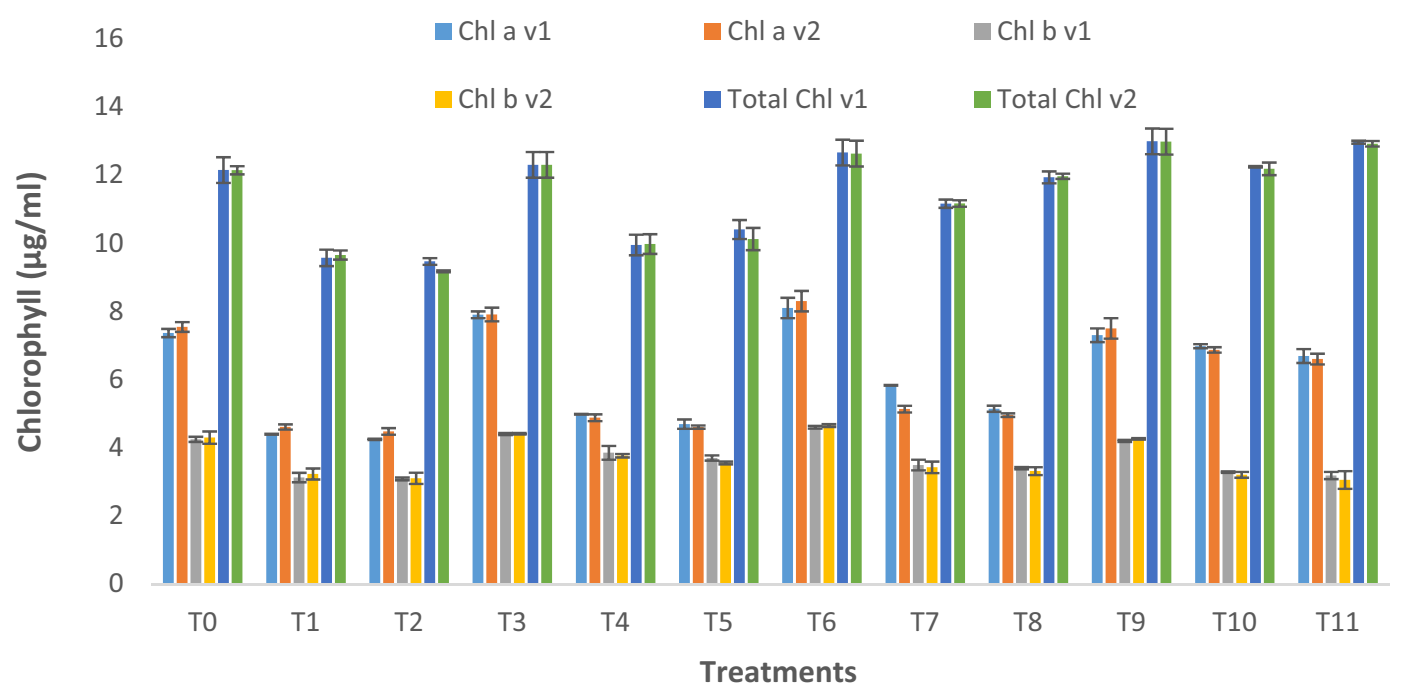

Figure 2. Chlorophyll a, chlorophyll b, and total chlorophyll contents of two lettuce varieties growing in crude oil contaminated, pyrochar, thermal desorption, and their combined application remediated soil. This data displays the means and standard deviation $(n=3)$. Different letters show significant differences $(\mathrm{p}<0.05)$. The detail of treatments is the same as in Fig. 1. 


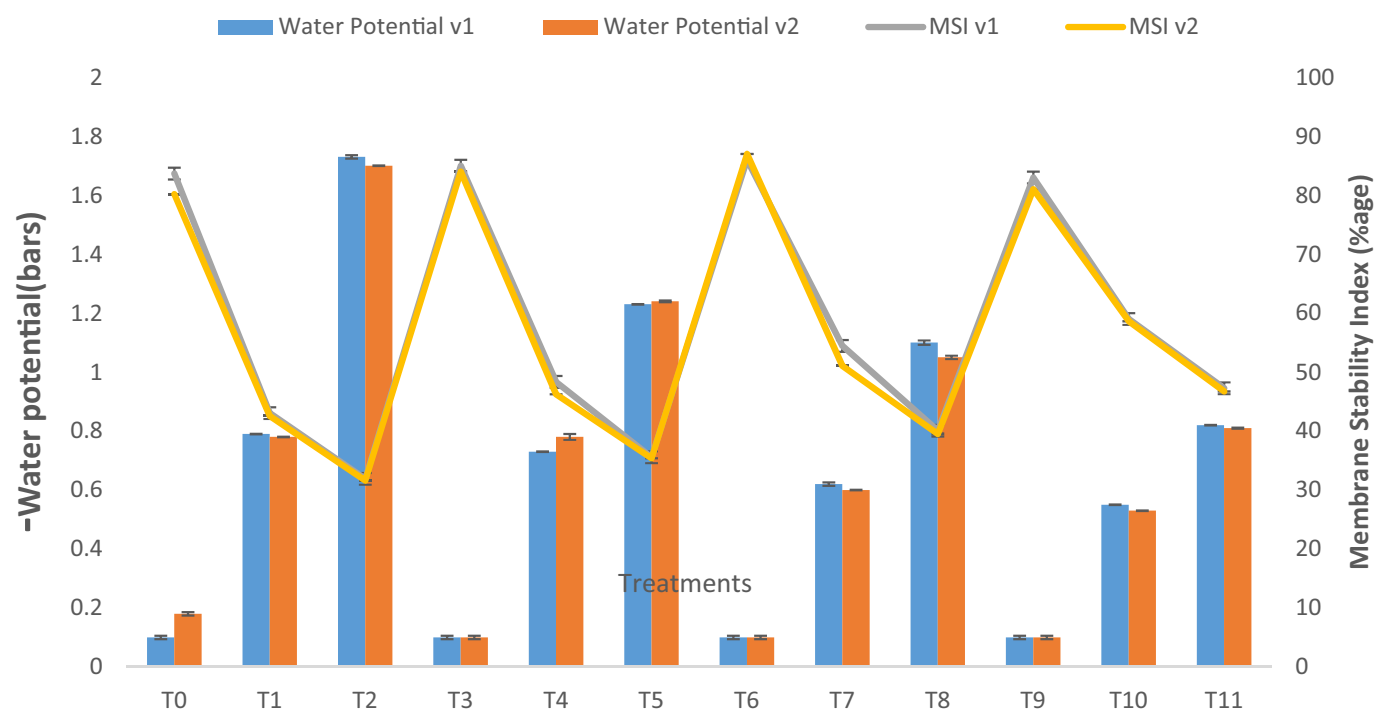

Figure 3. Water potential and membrane stability index of two lettuce varieties growing in crude oil contaminated, pyrochar, thermal desorption, and their combined application remediated soil. This data displays the means and standard deviation $(n=3)$. Different letters show significant differences $(p<0.05)$. The detail of treatments is the same as in Fig. 1.

Plant physiology. There was a decrease in Chlorophyll a (40\% and $45 \%$ decrease at $10-20 \%$ contamination, respectively), Chlorophyll b (26\% and $30 \%$ decrease at $10-20 \%$ contamination, respectively), and total chlorophyll (20\% and 25\% decrease at 10-20\% contamination, respectively) contents (Fig. 2), with an increase in the concentration of crude oil compared to non-polluted soils condition. Combined application treatment (Pyrochar and thermal desorption) improved the plant growth and total chlorophyll contents by 21 and $17 \%$ at $10-20 \%$ contamination respectively, as compared to the stressed plants.

Similarly, it was observed that the presence of $10 \%$ and $20 \%$ crude oil contamination decreased water potential by one and one and a half fold whereas combined application treatment improved water potential by $33.6 \%$ and $26.9 \%$ at respective low (10\%) and high (20\%) crude oil concentration (Fig. 3). In our observations, pyrochar increased the water potential of the leaf by $10 \%$ and $21 \%$ at $10-20 \%$ contamination, respectively. Whereas thermal desorption improved water potential by at $24 \%$ and $20 \%$ at $10-20 \%$ contamination, respectively Pyrolysis treatment remediated the soil and improved plant parameters.

Under $10 \%$ and $20 \%$ contamination crude oil contamination, the membrane stability index (MSI) decreased to $38.4 \%$ and $40.5 \%$ as compared to the control. Pyrochar addition resulted in a $32 \%$ and $21.6 \%$ increase in MSI in plants under both levels of crude oil. Thermal desorption showed an increase of $13 \%$ and $9.5 \%$ as compared to the stressed plants, whereas pyrochar showed a respective increase of $18 \%$ and $11 \%$, as compared to respective control. A similar response was shown by both varieties.

Plant biochemistry. Oil contamination stress caused an increase in proline $(33 \%$ and $43 \%$ decrease at $10-20 \%$ contamination, respectively), the free amino acid ( $12 \%$ and $22 \%$ decrease at $10-20 \%$ contamination, respectively), total protein ( $18 \%$ and $25 \%$ decrease at $10-20 \%$ contamination, respectively), and soluble sugar content (39\% and $60 \%$ decrease at $10-20 \%$ contamination, respectively) in both verities of lettuce (Fig. 4).

Combined application treatment (pyrochar and thermal desorption) increased proline contents by $25 \%$ and $32 \%$ under $10 \%$ and $20 \%$ contamination, respectively, pyrochar showed less increase in proline contents $(6 \%$ under control, $18 \%$ at $10 \%$ contamination and $9 \%$ at $20 \%$ contamination), whereas thermal desorption resulted in $(25 \%$ increase under control conditions, $30 \%$ at $10 \%$ contamination and $28 \%$ at $10 \%$ contamination., with respect to respective control).

A significant increase in total amino acid by combined application treatment was observed i.e. $29 \%$ and $16 \%$ with $10 \%$ and $20 \%$ contamination, respectively. Pyrochar increased total amino acid by $24 \%$ and $13 \%$ at $10-20 \%$ contamination, respectively, whereas thermal decontamination caused a $30 \%$ and $27 \%$ increase at $10-20 \%$ contamination, respectively.

The total soluble sugar concentration of lettuce plants was increased by the combined application by $37 \%$ and $22 \%$ at $10 \%$ and $20 \%$ contamination, respectively, however, pyrochar increased total soluble sugar by $26 \%$ and $20 \%$ at $10 \%$ and $20 \%$ contamination and thermal desorption increased 31 and $17 \%$ at $10 \%$ and $20 \%$ contamination, respectively.

Similarly, total protein contents increased by combined application treatment by $27 \%$ and $19 \%$ at $10 \%$ and $20 \%$ contamination, respectively. Pyrochar increased total protein by $20 \%$ and $17 \%$ at $10 \%$ and $20 \%$ contamination, respectively and thermal desorption increased and $22 \%$ and $18 \%$ at $10 \%$ and $20 \%$ contamination, respectively. Results were significant in both varieties. 


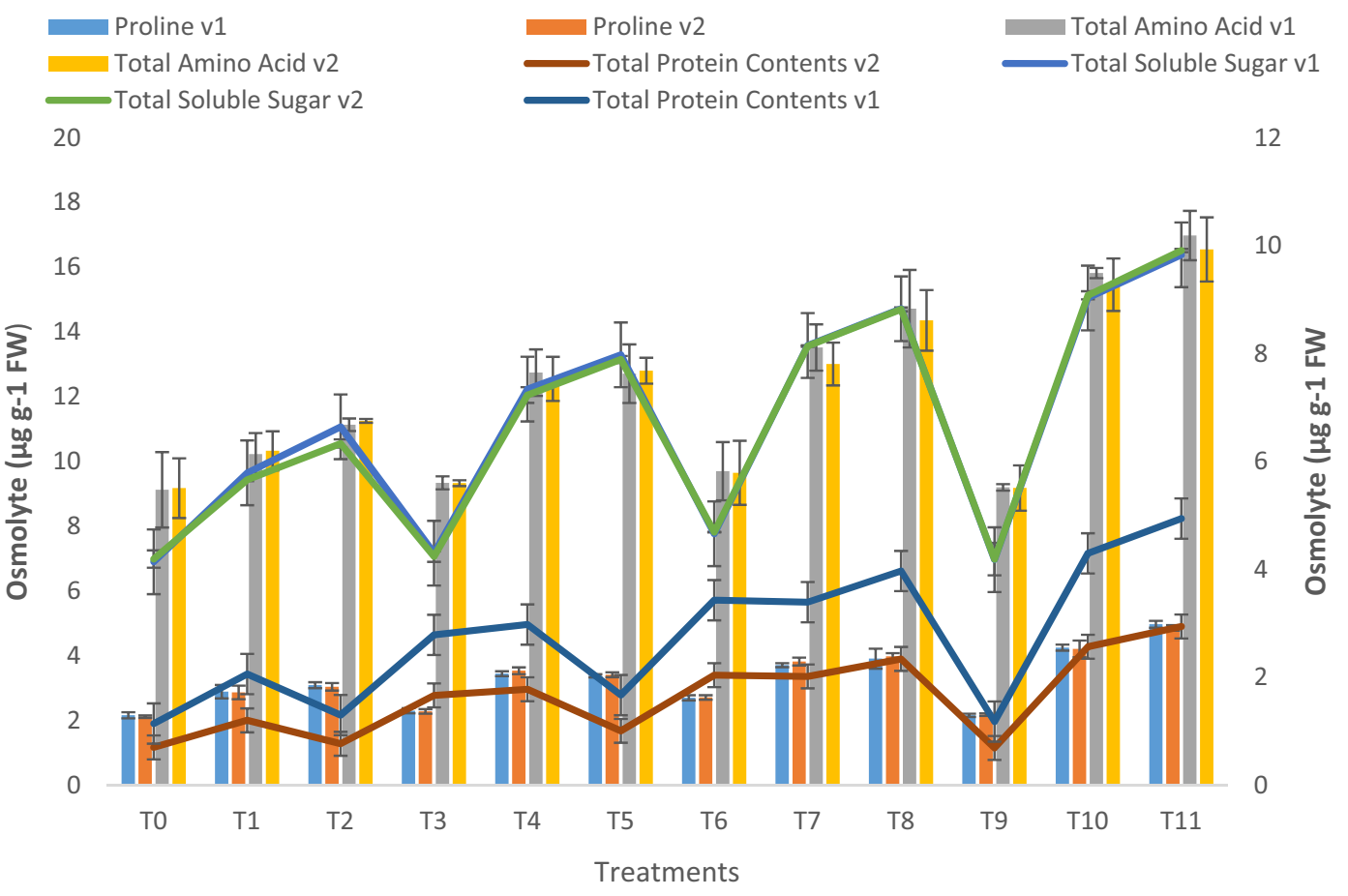

Figure 4. Proline contents, total amino acids, soluble sugar, and protein contents of two lettuce varieties growing in crude oil contaminated, pyrochar, thermal desorption, and their combined application remediated soil. This data displays the means and standard deviation $(n=3)$. Different letters show significant differences $(\mathrm{p}<0.05)$. The detail of treatments is the same as in Fig. 1.

Plant antioxidants. A notable rise in antioxidants was recorded in crude oil contaminated conditions (Fig. 5). Combined application treatment (Pyrochar and thermal desorption) increased superoxide dismutase activity by $140 \%$ and $100 \%$ in lettuce plants grown under $10 \%$ and $20 \%$ contamination, respectively. Pyrochar increased SOD by $55 \%$ and $34 \%$, thermal desorption by $82 \%$ and $68 \%$ at $10 \%$ and $20 \%$ contamination, respectively. Combined application treatment (Pyrochar and thermal desorption) treatment significantly reduces the adverse effects of crude oil contamination by increasing catalase activity by $53 \%$ and $27 \%$ in plants grown under $10 \%$ and $20 \%$ contamination, respectively. The increase in catalase by pyrochar was $28 \%$ and $13 \%$ and thermal desorption by $185 \%$ and $10 \%$ at $10 \%$ and $20 \%$ crude oil contamination, respectively. Similarly, lettuce plants when treated with combined application treatment (Pyrochar and thermal desorption) showed pronounced peroxidase activity by $49 \%$ and $46 \%$ at $10 \%$ and $20 \%$ contamination, respectively. Pyrochar treatment showed a significant increase of $9 \%$ and $13 \%$ in treated plants at $10 \%$ and $20 \%$ crude oil contamination. Whereas, thermal desorption increased peroxidase activity by $25 \%$ and $20 \%$ at $10 \%$ and $20 \%$ crude oil contamination, respectively. Both varieties of lettuce responded to bioremediation.

Heatmap responses of Pearson's correlation coefficient ( $r$ ). For heat map analysis the data of both lettuce seedlings under crude oil contamination stress were classified as hydrocarbon degradation, antioxidant enzymes, chlorophyll contents, osmolyte production, and each group showed positive correlations (Fig. 6). A comparative analysis of the factors related to hydrocarbon degradation (presented by green boxes) suggested that hydrocarbon degradation in contaminated soil had a positive correlation with amino acid, osmotic potential, soluble sugars, proline, MDA, SOD, POD, and CAT activities. While a negative correlation between total chlorophyll and MSI was observed. These results indicate that the degradation efficiency of combined application treatment (pyrochar and thermal desorption) for crude oil contamination resulted in better growth of lettuce plants.

\section{Discussions}

Crude oil contamination affects the agriculture sector particularly due to soil toxicity and reduced plant growth. Crude oil causes environmental risks in the soil ecological system ${ }^{16}$, by inhibition of plant growth, damage to soil structure, disturbance of soil water quality, and so on ${ }^{17}$. The present research was designed to observe the remediation potential of a novel combined application treatment (pyrochar and thermal desorption) technique, thermal desorption alone, and pyrochar alone in the oil-polluted soil. We found that these methods are not only beneficial to remediate the soil but also capable to overcome the toxic nature of crude oil.

Pyrochar improved soil characteristics not only under control conditions (without any contamination) but also under oil contamination. Thermal desorption had little effect on soil properties. The most promising results were shown by the combined application treatment. Soil amendments with combined application treatment 


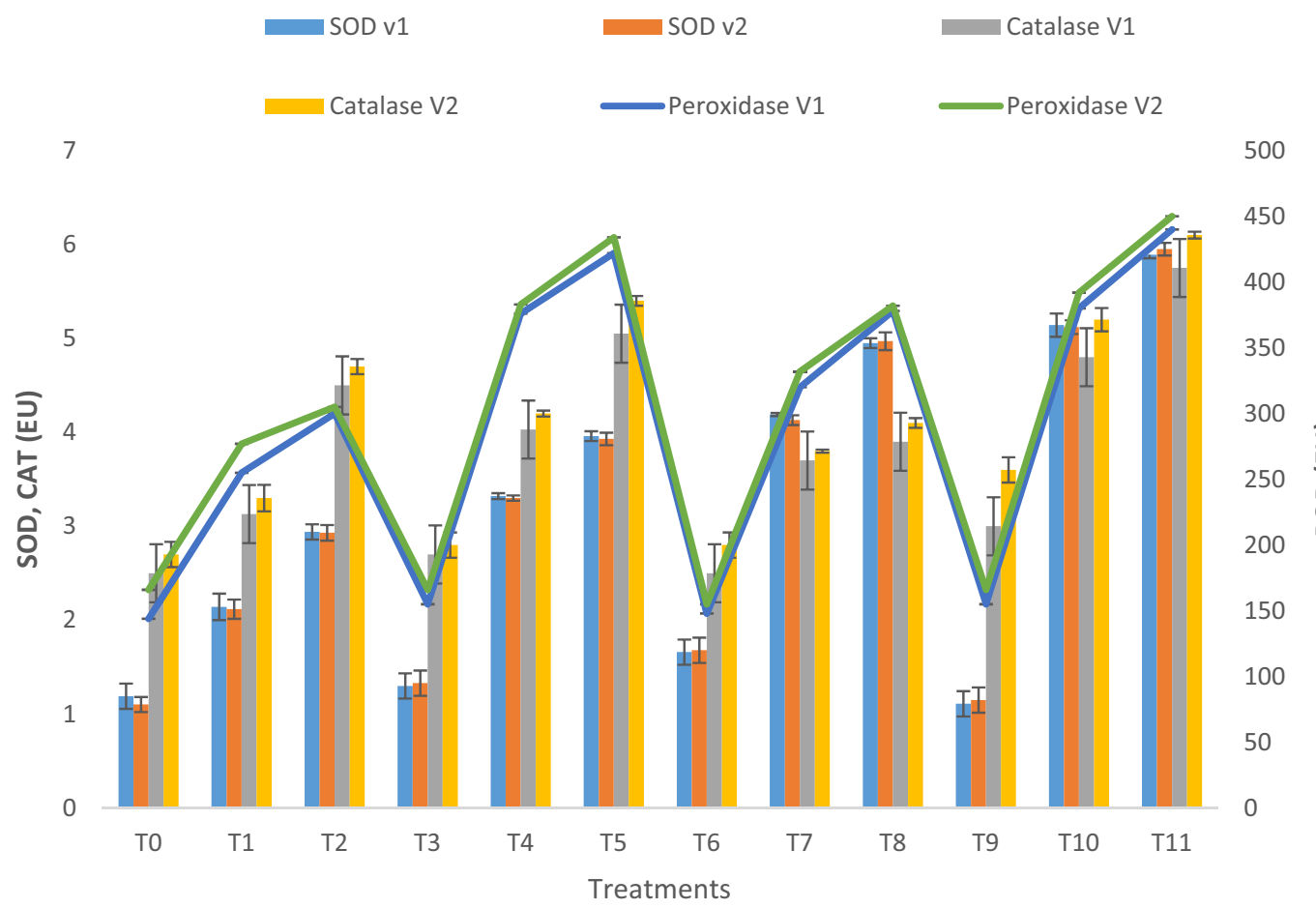

Figure 5. Antioxidant enzymes activity of two lettuce varieties growing in crude oil contaminated, pyrochar, thermal desorption, and their combined application remediated soil. This data displays the means and standard deviation $(n=3)$. Different letters show significant differences $(p<0.05)$. The detail of treatments is the same as in Fig. 1.
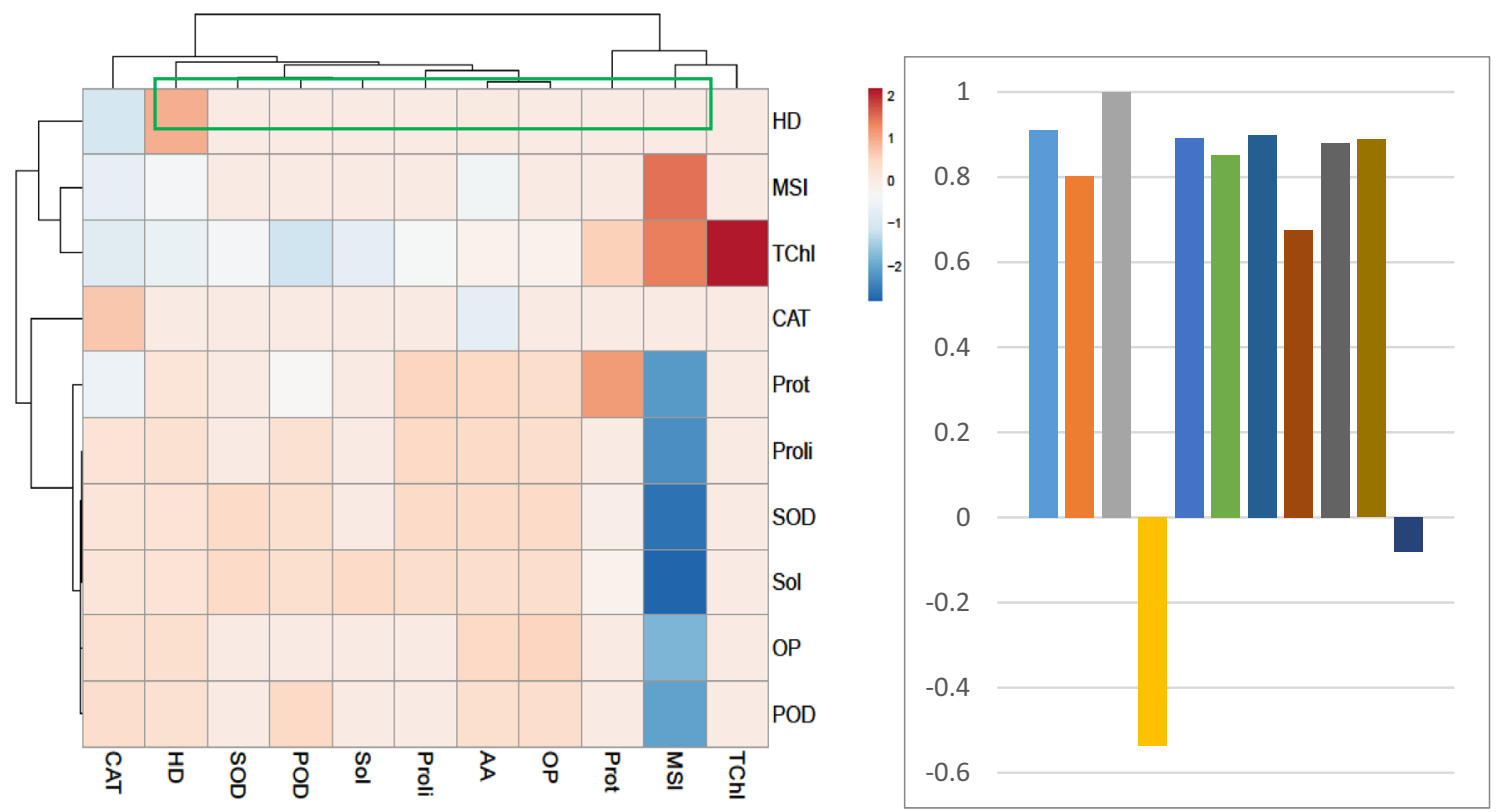

Figure 6. Heatmap responses of Pearson's Correlation Coefficient (r) for the crude oil degradation, antioxidant enzymes, chlorophyll contents, osmolyte production of lettuce leaves growing in crude oil contaminated soil treated with pyrochar, thermal desorption, and their combined application. Whereas TChl Total Chlorophyll, MSI Membrane Stability Index, CATL Leaves catalase, PODL Leaves peroxidase, SODL Leaves superoxide dismutase, AA Amioacid, Prol Proline, OP Osmotic potential, Sol Soluble Sugars. 
(pyrochar and thermal desorption) improved the properties of soil. In thermal desorption, the soil contaminants are desorbed, mobilized, and evaporated by the rise in temperature (from 100 to $600{ }^{\circ} \mathrm{C}$ ). Besides, thermal desorption also promotes biodegradation but decreases soil fertility ${ }^{18}$. Relatively limited studies are available on the application of pyrochar on the remediation of soil contaminated with organic pollutants ${ }^{19}$. However, little is currently known about the effects of pyrochar combined application with thermal desorption technique on the remediation of petroleum-contaminated soil. However, it has been observed in the present study that this combined application treatment effectively improved soil characteristics both at $10 \%$ and $20 \%$ crude oil contamination. This may be possibly due to the synergistic action of pyrochar and thermal desorption under their combined application in pyrochar. This is mainly due to the greater absorptive capacity of pyrocahr's greater surface area and microporous structure. Pyrochar enhances the nutrient content of soil for microbial populations and absorbed hydrophobic compounds more strongly. Improved microbial population stimulates the breakdown of absorbed hydrocarbons and used it as a source of carbon and energy. While thermal desorption accelerates the degradation of hydrocarbons. In thermal desorption, soil properties get changed and this type of soil is not supportive for the growth of plants. So in a combined application with pyrochar and thermal desorption, pyrochar improves the status of nutrients and holds hydrocarbons on its surface for degradation by microbes and thermal desorption and so this not only helps in degradation also enhances the nutrient status of the soil.

Treatment of soil with combined application treatment (pyrochar and thermal desorption) showed the most promising results in the degradation of crude oil. An inverse relationship exists between the rate of hydrocarbon degradation and the level of oil contamination as hydrocarbon degradation decreases with an increase in the oil contamination. This treatment degraded the crude oil contaminants in more members of low molecular weight compounds at both contamination levels (10\% and $20 \%)$. In combined application treatment, both pyrochar and thermal desorption techniques acted synergistically and their combined application significantly improved the degradation potential. Thermal desorption accelerates the degradations whereas pyrochar has also shown the potential of oil degradation and promotes microbial degradation ${ }^{20}$. Banat ${ }^{21}$ also reported that organic compounds in crude oil could be metabolized by oil-degrading microbes which are stimulated by soil amendment. Bioremediation of crude oil contaminated soil by stimulating the activity of bacteria by the addition of poultry manure ${ }^{22}$.

Removal of majority $n$-alkanes happened by pyrochar indicates that it has the potential in the remediation of crude oil. The results are consistent with the standards set for effective remediation processes ${ }^{23}$. Pyrochar can increase the sorption of organic pollutants ${ }^{24}$. Kang et al. ${ }^{18}$ attributed the thermal sorption to degradation of PAH. So, the combined application of pyrochar and thermal desorption can be preferentially used for oil-contaminated soils for biotreatment. The pyrochar improves the soil nutrient status for microorganisms $\mathrm{s}^{25}$ including organic carbons and binds hydrophobic organic compounds (HOCs), such as PAHs, more strongly. The thermal desorption technique is a very useful remediation technology because it is highly effective in decontaminating pollutants and organic chemicals. After thermal treatment, soil structure and properties were affected and the porosity of soil changes which is not easy to be recovered ${ }^{6}$. The synergism of pyrochar and thermal desorption resulted in enhanced degradation of n-alkanes at both low (10\%) and high (20\%) contamination levels.

Overall, crude oil contamination showed adverse effects on the growth of lettuce plants by reducing plant vigor, biomass, yellowing, and wilting of leaves. However, all soil treatments showed a significant reduction in crude oil toxicity and ultimately improvement in the growth of lettuce plants. A higher level of contamination (20\%) had more drastic reductions as compared to low (10\%) crude oil contamination). Application of combined application treatment (pyrochar and thermal desorption) results in enhanced seed germination, plant establishment, and growth; ultimately increasing crop productivity ${ }^{13}$. Pyrolysis of oil-contaminated soil results in higher exchange capacity, surface area, and direct nutrient additions and hence in better growth promotions ${ }^{26}$. The thermal desorption technique is a very useful remediation technology because it is highly effective in decontaminating pollutants and organic chemicals. After thermal treatment, soil structure and properties were affected and the porosity of soil changes which is not easy to be recovered ${ }^{6}$. No prior information is available about the response of plant germination to pyrochar application or its combined application with thermal desorption. However, our results are showing that this new technique of combined application treatment (pyrochar and thermal desorption) performed better than both pyrochar and thermal desorption techniques, alone, and thus its application can significantly improve plant growth and germination attributes.

Various studies have reported the role of these remediation techniques in the improvement of plant growth ${ }^{27}$ who also observed a decrease in biomass of plant under oil stress. Our results also relate with Laird et al. ${ }^{28}$, where fresh weight and dry weight increased because of the pyrochar amendment in soil. Thereby, pyrochar may reduce the leaching losses of nutrients by adding nutrients to the soil. Pyrolysis of soil was effective in soil remediation and soil biomass increased when compared with stress-imposed plants ${ }^{18}$. A combined application of both these treatments was most effective in the improvement of plant growth under crude oil contamination. This may be due to the reason that as it's a combined application technique, and combined effect of pyrochar and thermal desorption can complement each other and thus prove to be more effective.

Chlorophyll a, b, and total chlorophyll contents decreased with an increase in the concentration of crude oil compared to non-polluted soil conditions. Baruah et al. ${ }^{29}$, have been reported a similar decline in chlorophyll content of plants. Combined application treatment (pyrochar and thermal desorption) improved plant growth and chlorophyll content. Pyrochar and pyrolysis did improve plant pigments, but their effects were less pronounced. The increase in chlorophyll content might be due to an increase in nutrient uptake by the plant and a decrease in crude oil uptake ${ }^{30,31}$. Our results correlate with Ali et al. ${ }^{32}$, who reported that crude oil adversely affects the plant-water-soil relationship, resulting in chlorosis. To maintain the pressure potential, the plant needs to reduce the osmotic potential ${ }^{33}$. Although the use of pyrochar as a soil amendment is anticipated to increase the soil nutrients and water use efficiency and thereby crop productivity ${ }^{34}$. Pyrochar treated soil had better nutrient concentrations and water contents and thus improved plant water relations and ultimately increased plant photosynthetic pigments. 
Stress causes an increase in proline, free amino acid, total protein, and soluble sugar content in both verities of lettuce. Proline act as an osmotic stress protectant in response to environmental stress tolerance ${ }^{35}$. Under stressed conditions, proline plays a role in the stabilization of membranes, proteins, and other subcellular structures and protecting the cell by an increased level of reactive oxygen species. It helps to maintain the $\mathrm{pH}$ and turgor pressure of the cell ${ }^{36}$. Similar results were lined with Wang et al. ${ }^{23}$. A significant increase in total amino acid was observed i.e. $29 \%$ and $16 \%$ with 10 and $20 \%$ contamination, respectively. Amino acids act as osmoregulators in plants under stress conditions ${ }^{34}$. Under stress conditions, high soluble sugars regulate physiological roles such as photosynthesis, reserve mobilization, and exports while low sugar concentration promotes carbohydrate storage and senescence ${ }^{37}$. In present findings, though pyrochar and thermal pyrolysis treatment improved the proline, amino acids, and soluble sugar contents content under crude oil stress, the greatest increase was due to synergism of biochar and thermal desorption.

Antioxidants protect the cell from any damage caused by cytotoxic $\mathrm{O}_{2}$, by stopover its conversion to $\mathrm{H}_{2} \mathrm{O}_{2}$ and $\mathrm{O}_{2}$ in all the subcellular compartments. Combined application treatment (pyrochar and thermal desorption) treatment significantly improved plant antioxidant systems and helped plants to prevent damage by reactive oxygen species. Pyrochar treatment showed a significant increase of $9 \%$ and $13 \%$ in treated plants at $10 \%$ and $20 \%$ crude oil contamination. The remediation processes may increase the antioxidants by stimulating the intake of nitrogen and phosphorus, which interact with carbohydrates as non-enzymatic antioxidants ${ }^{38}$.

Correlation analysis showed that hydrocarbon degradation in contaminated soil is positively correlated with lettuce plant growth by regulating plant defense responses including antioxidant enzymes and osmolytes. This study establishes the relationship between the degradation potential of the new technique of combined application treatment (pyrochar and thermal desorption) with improved soil properties and ultimately in plant growth.

\section{Conclusion and future perspectives}

The results of the present research have proven the bioremediation potential of a new combined application treatment (pyrochar and thermal desorption) technique, for crude oil contamination which also showed significant growth potential for the lettuce plants. It enhanced the morphological, physiological, and biochemical parameters of the plant. Pyrochar and thermal pyrolysis treatments, alone, had their limitations in terms of slow degradation rates and less efficiency in plant growth, respectively. However, combined application treatment application proved effective in both processes and hence can be used at a larger scale on soils where crude oil pollution is a serious problem particularly for agricultural production.

\section{Methodology}

Preparation of soil. Non-polluted soil samples were obtained from the experimental field area of PMASAgriculture University, Rawalpindi, which had no prior exposure to hydrocarbons. The soil was sieved and was divided into three parts, $1 / 3$ of soil was kept clean and was taken as control, the second was Low Crude oil Contamination contaminated with $10 \%(\mathrm{w} / \mathrm{w})$ and the third part was High Crude oil Contamination contaminated with $20 \%$ crude oil (w/w), respectively.

Pyrochar was produced by pyrolysis of sawdust and shavings (Dalbergia sisso L.) collected from the local market. These were air-dried and pyrolyzed at $350^{\circ} \mathrm{C}$ in a muffle furnace, then grounded and was passed through a sieve of $200 \mu \mathrm{m}$ before use. Thermal desorption was done by soil pyrolysis. Soil samples were taken in preweighed crucibles and were pyrolyzed at $500{ }^{\circ} \mathrm{C}$ in muffle furnace with 60 min residence time $e^{18}$.

Earthen pots were filled with $10 \mathrm{~kg}$ soil and were maintained at $20 \%$ humidity by distilled water ${ }^{39}$. The soil was incubated for a period of 120 days before sowing. Two varieties of lettuce (V1 = Icerberg; V2 = Boston) were grown in control soil and soil contaminated with $10 \%$ and $20 \%$ crude oil. Three kinds of treatment methods were tested; Combined application of pyrochar and thermal desorption, pyrochar alone and thermal desorption alone under control soil and soil contaminated with $10 \%$ and $20 \%$ crude oil. The list of test conditions have been mentioned in Table 3.

Soil analysis. Soil samples from all treatments were tested for water holding capacity ${ }^{40}$. Saturated soil paste was used to measure $\mathrm{pH}$ and electrical conductivity ${ }^{41}$. Soil organic carbon was measured by the oxidation method of Walkley and Black ${ }^{42}$. The sodium acetate method was used to measure cation exchange capacity ${ }^{43}$. Soil texture, macro and micronutrients alaysis ${ }^{44}$, available nutrients analysis ${ }^{45}$ was also done.

Determination of biodegradation percentage. The percentage of oil degradation was calculated using the following formula:

$$
\text { Biodegradation }(\%)=\mathrm{TC}-\mathrm{TT} / \mathrm{TC} \times 100
$$

whereas TPH is the total petroleum hydrocarbon, TC is the TPH in the control, and TT is the TPH in the treatment.

Determination of hydrocarbons content of soil samples by GC-MS. Total Petroleum Hydrocarbons (TPH) of all soil samples were determined by EPA method 8015C (USEPA) with slight variation ${ }^{24}$. Briefly, extraction was done by using dichloromethane with the ultrasonication method and analyzed gravimetrically. The extracts were transferred into tare vials nearest $0.0001 \mathrm{~g}$ and expressed as $\mathrm{g} \mathrm{TPH} \mathrm{kg}{ }^{-1}$ dry soil. Organic compounds (i.e., C10 to C28) in the extracts were quantified by an Agilent 6890 Gas Chromatography coupled with Time-of-flight Mass Spectrometry and equipped with silica capillary column. 


\begin{tabular}{|l|l|}
\hline \multicolumn{2}{|l|}{ Lettuce varieties/germplasm } \\
\hline V1 & Lettuce variety iceberg) \\
\hline V2 & Lettuce variety boston \\
\hline Treatments \\
\hline T0 & Control soil (Uncontaminated soil) \\
\hline T1 & $10 \%$ crude oil contaminated soil \\
\hline T2 & $20 \%$ crude oil contaminated soil \\
\hline T3 & Pyrochar Treated control soil \\
\hline T4 & Pyrochar + 10\% crude oil contaminated soil \\
\hline T5 & Pyrochar $+20 \%$ crude oil contaminated \\
\hline T6 & Thermal desorption control soil \\
\hline T7 & Thermal desorption $+10 \%$ crude oil contaminated soil \\
\hline T8 & Thermal desorption $+20 \%$ crude oil contaminated soil \\
\hline T9 & Combined application of pyrochar and thermal desorption treated control soil \\
\hline T10 & Combined application of pyrochar and thermal desorption treated $+10 \%$ crude oil contaminated soil \\
\hline T11 & Combined application of pyrochar and thermal desorption treated $+20 \%$ crude oil contaminated soil \\
\hline
\end{tabular}

Table 3. Details of treatments and their abbreviation.

Potential of remediation techniques for germination attributes of the lettuce plant. A germination experiment was performed in the physiology lab of PMAS Arid Agriculture University, Rawalpindi. Seeds of two lettuce varieties (Iceberg and Boston) obtained from the National Agricultural Research Centre Islamabad, were surface sterilized by treating with sodium hypochlorite (1\%) solution for $5 \min ^{46}$. After that, seeds were successively washed with distilled water and were placed in Petri plates. There was a total of eleven treatments in this experiment which are described in Supplementary Table 1. Germination percentage, seedling vigor index, and promptness index ${ }^{46}$ were measured for each treatment.

Potential of remediation techniques for growth attributes of the Lettuce plant. A pot experiment was conducted in the greenhouse of the Botany Department, PMAS- AAUR, Rawalpindi. A complete randomized design (CRD) was applied with three replications. Treatments were the same as described in the above section. Seven sterilized seeds of each variety were sown per pot which was later thinned. Plants were harvested after 45 days of sowing. Fresh and dry biomass was recorded. Leaf area was measured with the help of a leaf area meter. All the samples were collected in zipper bags and stored at $-20^{\circ} \mathrm{C}$ freezer for further biochemical assays. In morphological parameters root length, shoot length, shoot fresh/dry weight, root fresh/dry weight, and leaf area were analysed.

Physiological analysis. Lettuce leaves were analyzed for water potential, using the pressure chamber according to the protocol of Scholander ${ }^{47}$. Excised leaves were inserted in the specimen holder of the pressure vessel of the instrument. The pressure was gradually built up within the pressure vessel until the sap started to ooze out from the exposed cut end of the leaf. Reading at this point corresponded to the negative force with which the water was held within that leaf sample. It was noted and expressed in-MPa.

The osmotic potential was determined by opting for the procedure of Capell and Doerffling ${ }^{48}$. Leaves from each treatment were placed in a $3 \mathrm{ml}$ plastic syringe and stored at $-20^{\circ} \mathrm{C}$ freezer. After a few days, when the leaves became frozen, these syringes were taken out and pressed to collect the leaf sap from the thawed samples in Eppendorf tubes. The $10 \mu \mathrm{L}$ from each sample was taken readings were obtained by vapor pressure osmometer (VIESCOR $5520 \mathrm{VX} \mathrm{R}$ ) in $\mathrm{mmol} / \mathrm{kg}$ and these values were converted in to (-MPA) with the help of this formula

$$
\text { Osmotic potential }=\text { Osmolality }(\mathrm{mmol}) \times 0.831 \times 10^{-5} \mathrm{~T}\left({ }^{\circ} \mathrm{K}\right)
$$

where $\mathrm{T}$ is temperature expressed in ${ }^{\circ} \mathrm{K}$.

For determining membrane stability index (MSI), Premchandra et al. ${ }^{49}$, method which, was used. For this purpose, $100 \mathrm{mg}$ leaf discs were carefully washed first with tap water and then with double distilled water. After washing, leaf discs were heated in $10 \mathrm{~mL}$ double distilled water at $40^{\circ} \mathrm{C}$ in a water bath for $30 \mathrm{~min}$. After $30 \mathrm{~min}$, electrical conductivity $\left(\mathrm{C}_{1}\right)$ of this sample was noted using the EC meter. After noting the first EC reading the same sample was placed in a water bath at $100^{\circ} \mathrm{C}$ for $10 \mathrm{~min}$. and after this process, electrical conductivity $\left(\mathrm{C}_{2}\right)$ was again recorded. For calculating the Membrane stability index following equation was used

$$
\text { MSI }=\left(1-\frac{C 1}{C 2}\right) \times 100
$$

Arnon $^{50}$ method was opted for estimating chlorophyll and carotenoid content of leaf samples. Leaves were weighed and then crushed in a clean pestle and mortar. $5 \mathrm{~mL}$ of $80 \%$ acetone was added to each crushed sample. This sample was then centrifuged, and the supernatant was taken into the cuvette of the spectrophotometer. The absorbance of the extract was recorded at different wavelengths i.e., $663 \mathrm{~nm}$ and $645 \mathrm{~nm}$ and $470 \mathrm{~nm}$. The 
values of chlorophyll a, b, total chlorophyll, and carotenoid were calculated by following formulae given by Lichtenthaler and Welburn ${ }^{51}$

$$
\begin{gathered}
\text { Chlorophyll } a(\mu \mathrm{g} / \mathrm{mL})=12.21\left(\mathrm{~A}_{663}\right)-2.81\left(\mathrm{~A}_{645}\right) \\
\text { Chlorophyll } b(\mu \mathrm{g} / \mathrm{mL})=20.13\left(\mathrm{~A}_{645}\right)-5.03\left(\mathrm{~A}_{663}\right) \\
\text { Total chlorophyll }(\mu \mathrm{g} / \mathrm{mL})=20.2\left(\mathrm{~A}_{645}\right)+8.02\left(\mathrm{~A}_{663}\right) \\
\text { Carotenoid content }(\mu \mathrm{g} / \mathrm{mL})=\left[1000 \mathrm{~A}_{470}-3.27(\text { chlorophyll } a)-104(\text { chlorophyll } b)\right] / 227
\end{gathered}
$$

Biochemical analysis. Proline was measured following the method of Bates et al. ${ }^{52}$. Leaf material (0.1 g) was homogenized with $4 \mathrm{~mL}$ sulfosalicylic acid (3.0\%) with the help of pestle and mortar. This sample was previously kept overnight at $5{ }^{\circ} \mathrm{C}$. The suspension was centrifuged at room temperature at $3000 \mathrm{rpm}$ for $5 \mathrm{~min}$; Supernatant was mixed with $4 \mathrm{~mL}$ acetic ninhydrin reagent and mechanically shaken and the contents in the tubes were heated for one hour at $100^{\circ} \mathrm{C}$. After cooling the content in the tubes and this solution was extracted with $4 \mathrm{~mL}$ of toluene with the help of a separating funnel. Then the toluene layer was separated and its absorbance was recorded with a spectrophotometer at $520 \mathrm{~nm}$. The concentration of the proline of these unknown samples was calculated by using the standard curve of proline.

Soluble protein was determined following the method of Lowry et al..$^{53}$, using Bovine Serum Albumin (BSA) as standard. Fresh leaves $(0.1 \mathrm{~g})$ were ground in $1 \mathrm{~mL}$ of sodium phosphate buffer $(\mathrm{pH} 7.5)$ with the help of mortar and pestle and this mixture was centrifuged at $3000 \mathrm{rpm}$ for $10 \mathrm{~min}$. The supernatant $(0.1 \mathrm{~mL})$ was taken in the test tubes. Total volume was made $1 \mathrm{~mL}$ with the help of Distilled water. $1 \mathrm{mLof}$ reagent made by mixing $50 \mathrm{~mL}$ of solution $\mathrm{A}\left(2.0 \mathrm{~g} \mathrm{Na}_{2} \mathrm{CO}_{3}\right) 0.4 \mathrm{~g} \mathrm{NaOH}(0.1 \mathrm{~N})$ and $1 \mathrm{~g} \mathrm{Na}-\mathrm{K}$ tartrate was dissolved in $100 \mathrm{~mL}$ of distilled water) and $1 \mathrm{~mL}$ of solution $\mathrm{B}\left(\mathrm{CuSO}_{4} \cdot 5 \mathrm{H}_{2} \mathrm{O}(0.5 \mathrm{~g})\right.$ dissolved in $100 \mathrm{~mL}$ of distilled water) was added. After shaking for $10 \mathrm{~min} .0 .1 \mathrm{~mL}$ of Folin phenol reagent (diluted with distilled water in the ratio 1:1) was added. After $30 \mathrm{~min}$ absorbance of each sample was recorded at $650 \mathrm{~nm}$ after $30 \mathrm{~min}$.

For the quantification of free amino acids, the leaf sample (each $0.5 \mathrm{~g}$ ) was ground in $10 \mathrm{~mL}$ of potassium phosphate buffer. The mixture was centrifuged at $12,000 \times \mathrm{g}$ at $4{ }^{\circ} \mathrm{C}$. To $1 \mathrm{~mL}$ of the supernatant, $1 \mathrm{~mL}$ of ninhydrin $(2 \%)$ and $1 \mathrm{~mL}$ of pyridine (10\%) were added, and the mixture was placed in a water bath for $30 \mathrm{~min}$. After cooling all samples, absorbance was read at $750 \mathrm{~nm}$ using a spectrophotometer ${ }^{54}$.

Dubois et al. ${ }^{55}$, the method was used for estimating the sugar content of leaves. Leaf material $(0.5 \mathrm{~g})$ was crushed with the help of a clean pestle and mortar, $10 \mathrm{~mL}$ of distilled water was added to this material. Then this homogenized material was filtered. $0.1 \mathrm{~mL}$ of the filtrate from each sample was taken in the separate test tube

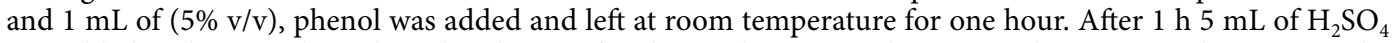
was added to the test tubes. Then absorbance of each sample was noted at $420 \mathrm{~nm}$ by a spectrophotometer. The standard curve of glucose solution of known concentration was used to estimate the sugar content of the samples.

Enzyme extract was prepared by grinding one gram of leaf in liquid nitrogen. The obtained powder was added in $10 \mathrm{~mL}$ of $50 \mathrm{mM}$ phosphate buffer ( $\mathrm{pH} 7.0)$ and was mixed with $1 \mathrm{mM}$ Ethylene Diamine Tetra Acetic acid (EDTA) and $1 \%$ polyvinylpyrrolidone (PVP). The whole mixture was centrifuged at $13,000 \times g$ for $20 \mathrm{~min}$ at $4{ }^{\circ} \mathrm{C}$. The supernatant was used for the enzyme assay.

The catalase (CAT) content was estimated by observing the degradation of $\mathrm{H}_{2} \mathrm{O}_{2}$ at $240 \mathrm{~nm}^{56}$. Catalase activity ( $\mathrm{U}$ mg protein ${ }^{-1}$ ) was calculated from the molar absorption coefficient of $40 \mathrm{~mm}^{-1} \mathrm{~cm}^{-1}$ for $\mathrm{H}_{2} \mathrm{O}_{2}$. Peroxidase dismutase (POD) was determined by following the procedure of $\mathrm{Ra}^{57}$. The reaction mixture consisted of 10 $\mu \mathrm{L}$ of crude enzyme extract, $20 \mu \mathrm{L}$ of $100 \mathrm{mM}$ guaiacol, $10 \mu \mathrm{L}$ of $100 \mathrm{mM} \mathrm{H}_{2} \mathrm{O}_{2}$, and $160 \mu \mathrm{L}$ of $50 \mathrm{mM}$ sodium acetate ( $\mathrm{pH}$ 5.0). Absorbance was recorded at $450 \mathrm{~nm}$.

Superoxide dismutase (SOD) activity was determined by the method of Beauchamp and Fridovich ${ }^{58}$. The reaction mixture $(3 \mathrm{~mL})$ was composed of $13 \mathrm{mM}$ methionine, $0.075 \mathrm{mM}$ NBT, $0.1 \mathrm{mM}$ EDTA, $0.002 \mathrm{mM}$ riboflavin, and $0.1 \mathrm{~mL}$ of enzyme extract in $50 \mathrm{mM}$ phosphate buffer $(\mathrm{pH} 7.8)$. The mixture in the tube was placed under fluorescent light for $15 \mathrm{~min}$ thereafter the reaction was stopped by turning the lights off. A complete reaction mixture (non-irradiated) was used as a blank. The absorbance was read at $560 \mathrm{~nm}$ with a spectrophotometer. One unit of SOD activity was defined as the amount of enzyme, which reduced the absorbance reading by $50 \%$ as compared to the control (lacking enzyme).

Statistical analysis. The morphological, physiological, and biochemical parameters were calculated, and the data were subjected to the analysis of variance (ANOVA) by using statistics 8.1 software. Mean values were compared by the least significant difference (LSD) at $\mathrm{P} \leq 0.05^{59}$ Heatmap for correlation coefficient was generated using web tool clustvis (https://biit.cs.ut.ee/clustvis/).

Received: 12 July 2020; Accepted: 18 January 2021

Published online: 02 February 2021 


\section{References}

1. Gordon, G., Stavi, I., Shavit, U. \& Rosenzweig, R. Oil spill effects on soil hydrophobicity and related properties in a hyper-arid region. Geoderma 312, 114-120 (2018).

2. Saini, H. \& Arya, I. D. Bioremediation of oil polluted soil: Effect on hill bamboo (Drepanostachyum falcatum) plant emergence and height. J. Agric. Biotechnol. Sustain. Dev. 8(6), 46-52 (2016).

3. Ramirez, M. I., Arevalo, A. P., Sotomayor, S. \& Bailon-Moscoso, N. Contamination by oil crude extraction-Refinement and their effects on human health. Environ. Pollut. 231, 415-425 (2017).

4. Vidonish, J. E. et al. Pyrolytic treatment and fertility enhancement of soils contaminated with heavy hydrocarbons. Environ. Sci. Technol. 50, 2498-2506 (2016).

5. Ren, J., Song, X. \& Ding, D. Sustainable remediation of diesel-contaminated soil by low temperature thermal treatment: Improved energy efficiency and soil reusability. Chemosphere 241, 124952 (2020).

6. Yi, Y. M., Park, S., Munster, C., Kim, G. \& Sung, K. Changes in ecological properties of petroleum oil-contaminated soil after lowtemperature thermal desorption treatment. Water Air Soil Pollut. 227, 108 (2016).

7. Liu, Y. et al. Effect of pyrochar and hydrochar on water evaporation in clayey soil under greenhouse cultivation. Int. J. Environ. Res. Public Health 16(14), 2580. https://doi.org/10.3390/ijerph16142580 (2019).

8. Gai, C., Chen, M., Liu, T., Peng, N. \& Liu, Z. Gasification characteristics of hydrochar and pyrochar derived from sewage sludge. Energy 113, 957-965 (2016).

9. Abdul-Ganiyu, S., Alhassan, A. L. \& Adongo, T. A. Effect of different water application schedules on the growth and yield of loose leaf lettuce (Lactuca sativa var. crispa) at Golinga Irrigation Scheme in the Tolon District of Northern Region, Ghana. Green. J. Agric. Sci. 5(5), 159-166 (2015).

10. Júnior, F. M. R. D. S., Garcia, E. M., Baisch, P. R. M., Mirlean, N. \& Muccillo-Baisch, A. L. Assessment of a soil with moderate level of contamination using lettuce seed assay and terrestrial isopods assimilation assay. Soil Water Res. 8(2), 56-62 (2013).

11. Eom, I. C., Rast, C., Veber, A. M. \& Vasseur, P. Ecotoxicity of a polycyclic aromatic hydrocarbon (PAH)-contaminated soil. Ecotoxicol. Environ. Saf. 67, 190-205 (2007).

12. Martí, E., Sierra, J., Sanchez, M., Cruañas, R. \& Garau, M. A. Ecotoxicological tests assessment of soils polluted by chromium(VI) or pentachlorophenol. Sci. Total Environ. 378, 53-57 (2007).

13. Brennan, A., Jiménez, E. M., Alburquerque, J. A., Knapp, C. W. \& Switzer, C. Effects of biochar and activated carbon amendment on maize growth and the uptake and measured availability of polycyclic aromatic hydrocarbons (PAHs) and potentially toxic elements (PTEs). Environ Pollut. 193, 79-87 (2014).

14. Evangelou, M. W. H., Brem, A., Ugolini, F., Abiven, S. \& Schulin, R. oil application of biochar produced from biomass grown on trace element contaminated land. J. Environ. Manage. 146, 100-106 (2014).

15. Mia, S., Dijkstra, F. A. \& Singh, B. Long-term ageing of biochar: A molecular understanding with agricultural and environmental implications. Adv. Agron. 141, 1-51 (2017).

16. Wang, B. X. et al. Degradation of petroleum hydrocarbons (C6-C40) and crude oil by a novel Dietzia strain. Bioresour. Technol. 102, 7755-7761 (2011).

17. Han, T., Zhao, Z., Bartlam, M. \& Wang, Y. Combination of biochar amendment and hytoremediation for hydrocarbon removal in petroleum-contaminated soil. Environ. Sci. Pollut. Res. 23, 21219-21228 (2016).

18. Kang, C. U. et al. Pyrolytic remediation of crude oil-contaminated soil. Sci. Total Environ. 713, 136498 (2020).

19. Ahmad, M. et al. Biochar as a sorbent for contaminant management in soil and water: A review. Chemosphere 99, 19-33 (2014).

20. Ogbonnaya, U. \& Semple, K. T. Impact of biochar on organic contaminants in soil: A tool for mitigating risk?. Agronomy 3, 349-375 (2013).

21. Banat, I. M. et al. Microbial biosurfactants production, applications and future potential. Appl. Microbiol. Biotechnol. 87, 427-444 (2010).

22. Alfreda, O. N. \& Ekene, G. O. Bioremediation of crude oil polluted soil using bacteria and poultry manure monitored through soybean productivity. Polish J. Environ. Studies 21(1), 171-176 (2012).

23. Wang, Y. et al. Effects of biochar on photosynthesis and antioxidative system of Malus hupehensis Rehd. seedlings under replant conditions. Sci. Horticult. 175, 9-15 (2014).

24. Chen, B. \& Yuan, M. Enhanced sorption of polycyclic aromatic hydrocarbons by soil amended with biochar. J. Soils Sediments 11(1), 62-71 (2011).

25. Ding, Y. et al. Biochar to improve soil fertility: A review. Agron. Sustain. Dev. 36, 36 (2016).

26. Gronwald, M., Don, A., Tiemeyer, B. \& Helfrich, M. Effects of fresh and aged chars from pyrolysis and hydrothermal carbonization on nutrient sorption in agricultural soils. Soil 1, 475-489 (2015).

27. Shahid, H., Iqbal, M., Shafiq, M. \& Athar, M. Effects of crude oil polluted soil on the seedling growth of Pennisetum Blaucum (L.). J. Plant Dev. 24, 33-43 (2017).

28. Laird, D. A. et al. Impact of biochar amendments on the quality of a typical Midwestern agricultural soil. Geoderma 158(3-4), 443-449 (2010).

29. Baruah, P., Saikia, R. R., Baruah, P. P. \& Deka, S. Effect of crude oil contamination on the chlorophyll content and morphoanatomyof Cyperus brevifolius (Rottb) Hassk. Environ. Sci. Pollut. Res. 21(21), 12530-12538 (2014).

30. Mosa, A., El-Banna, M. F. \& Gao, B. Biochar filters reduced the toxic effects of nickel on tomato (Lycopersicum esculentum L.) grown in nutrient film technique hydroponic system'. Chemosphere 149, 254-262 (2016).

31. Rehman, M. Z. U. et al. Contrasting effects of Biochar, compost and farm manure on alleviation of nickel toxicity in maize in relation to plant growth, photosynthesis and metal uptake. Ecotoxicol. Environ. Saf. 133, 218-225 (2016).

32. Ali, B. A. A., Ali, H. H. \& Shaker, G. A. The impact of ascending levels of crude oil pollution on growth of olive (Olea europaea Linn.) seedlings. Ibn AL-Haitham J. Pure Appl. Sci. 22(3), 1 (2017).

33. Borgo, L., Marur, C. J. \& Vieira, L. G. E. Effects of high proline accumulation on chloroplast and mitochondrial ultrastructure and on osmotic adjustment in tobacco plants. Acta Sci. Agron. 37(2), 191-199 (2015).

34. Haider, G. et al. Biochar but not humic acid product amendment affected maize yields via improving plant-soil moisture relations. Plant Soil 395, 141-157 (2015).

35. Bashir, A. et al. Plant-derived compatible solutes proline betaine and betonicine confer enhanced osmotic and temperature stress tolerance to Bacillus subtilis. Microbiology 160(10), 2283-2294 (2014).

36. Szabados, L. \& Savouré, A. Proline: A multifunctional amino acid. Trends Plant Sci. 15(2), 89-97 (2010).

37. Sami, F., Yusuf, M., Faizan, M., Faraz, A. \& Hayat, S. Role of sugars under abiotic stress. Plant Physiol. Biochem. 109, 54-61 (2016).

38. Madanala, R. et al. A highly stable $\mathrm{Cu} / \mathrm{Zn}$ superoxide dismutase from Withania somnifera plant: Gene cloning, expression and characterization of the recombinant protein. Biotechnol. Lett. 33(10), 2057-2063 (2011).

39. Polti, M. A., Aparicio, J. D., Benimeli, C. S. \& Amoroso, M. J. Role of actinobacteria in bioremediation. In Microbial Biodegradation and Bioremediation (ed. Das, S.) 269-286 (Elsevier, New York, 2014).

40. Priha, O. \& Smolander, A. Nitrogen transformations in soil under Pinus sylvestris, Picea abies and Betula pendula at two forest sites. Soil Biol. Biochem. 31, 965-977 (1999).

41. Radojević, M. \& Bashkin, V. N. Practical Environmental Analysis 20 (The Royal Society of Chemistry, London, 1999). 
42. Walkley, A. \& Black, I. A. An examination of Degtjareff method for determining soil organic matter and a proposed modification of the chromic acid titration method. Soil Sci. 37, 29-37 (1934).

43. Sumner, M. E. \& Miller, W. P. Cation exchange capacity and exchange coefficients. in Methods of soil analysis. (ed. Sparks, D. L) 1201-1229 (Part 2: Chemical properties. SSSA, Madison, WI, 1996).

44. Soltanpur, P. N. \& Schwab, A. P. A new soil test for simultaneous extraction of macro-micronutrients in soil. Commun. Soil Sci. Plant Anal. 8, 195-207 (1977).

45. U.S. EPA. 2007. "Method 3051A (SW-846): Microwave Assisted Acid Digestion of Sediments, Sludges, and Oils," Revision 1. Washington, DC

46. Noreen, Z., Muhammad, A. \& Mahmood, U. H. Inter accessional variations for salt tolerance in pear (Pisum Sativum L.) at germination and screening stage. Pak. J. Bot. 39(6), 2075-2085 (2007).

47. Scholander, P. F., Hammer, H. T., Bradsteel, E. P. \& Henningsen, E. A. Sap pressure in vascular plants. Science 148, 339-346 (1965).

48. Capell, B. \& Doerffling, K. Genotype-specific difference in chilling tolerance of maize in relation to chilling-induced changes in water status and abscisic acid accumulation. Physiol. Plant 88, 638-646 (1993).

49. Premchandra, G. S., Saneoka, H. \& Ogata, S. Cell membrane stability, an indicator of drought tolerance as affected by applied nitrogen in soybean. J. Agric. Sci. Camb. 115, 63-66 (1990).

50. Arnon, D. I. Copper enzymes in isolated chloroplasts polyphenoloxidase in Beta vulgaris. Plant Physiol. 24, 1-15 (1949).

51. Lichtenthaler, H. K. \& Wellburn, W. R. Determination of total carotenoids and chlorophylls a and b of leaf extracts in different solvents. Biochem. Soc. Trans. 11, 591-592 (1983).

52. Bates, L. S., Waldern, R. \& Teare, I. D. Rapid determination of free proline for water stress studies. Plant Soil 39, 205-207 (1973).

53. Lowry, O. H., Rosebrough, N. J., Farr, A. L. \& Randall, R. J. Protein measurement with Folin phenol reagent. J. Biol. Chem. 193, 265-275 (1951).

54. Hamilton, P. B. \& Van Slyke, D. D. Amino acid determination with ninhydrin. J. Biol. Chem. 150, 231-233 (1943).

55. Dubois, M. K. A., Gilles, J. K., Hamilton, P. A. \& Smith, F. Colorimetric method for determination of sugars and related substances. Anal. Chem. 28, 350-356 (1956)

56. Aebi, H. Catalase in vitro in Methods in Enzymology (Volume 105) 121-126 (Academic Press, Cambridge, 1984).

57. Rao, M. V., Paliyath, G. \& Ormrod, D. P. Ultraviolet-B- and ozone induced biochemical changes in antioxidant enzymes of Arabidopsis thaliana. Plant Physiol. 110, 125-136 (1996).

58. Beauchamp, C. \& Fridovich, I. Superoxide dismutase Improved assays and an assay applicable to acrylamide gel. Anal. Biochem. 44, 276-287 (1971).

59. Steel, R. G. D. \& Torrie, G. H. A Biometrical Approach in Principles and Procedures of Statistics 2nd edn. (McGraw Hill Book Co Inc., New York, 1980).

\section{Author contributions}

N.I.: Conceptualization, Writing-Original Draft, Supervision. U.S.: Investigation, Writing-Original Draft. M.S.: Investigation (GC-MS), Writing-Original Draft. N.A.: Writing-Original Draft. H.Y.: Formal Analysis WritingReview and Editing. W.K.: Formal Analysis, Writing-Review and Editing. S.I. Writing-Review and Editing.

\section{Competing interests}

The authors declare no competing interests.

\section{Additional information}

Supplementary Information The online version contains supplementary material available at https://doi. org/10.1038/s41598-021-82243-y.

Correspondence and requests for materials should be addressed to N.I.

Reprints and permissions information is available at www.nature.com/reprints.

Publisher's note Springer Nature remains neutral with regard to jurisdictional claims in published maps and institutional affiliations.

(c) (i) Open Access This article is licensed under a Creative Commons Attribution 4.0 International cc) License, which permits use, sharing, adaptation, distribution and reproduction in any medium or format, as long as you give appropriate credit to the original author(s) and the source, provide a link to the Creative Commons licence, and indicate if changes were made. The images or other third party material in this article are included in the article's Creative Commons licence, unless indicated otherwise in a credit line to the material. If material is not included in the article's Creative Commons licence and your intended use is not permitted by statutory regulation or exceeds the permitted use, you will need to obtain permission directly from the copyright holder. To view a copy of this licence, visit http://creativecommons.org/licenses/by/4.0/.

(C) The Author(s) 2021 